Conclusions: As early as wk14, IV GLM demonstrated clinically meaningful improvements in skin $\mathrm{PsO}$ irrespective of MTX use and nail PsO. Improvement in DLQI was seen as early as wk8, w/continued improvement at wks 14 and 24.

Disclosure of Interest: P. Mease Grant/research support from: Janssen Research and Development, LLC, M. Husni Grant/research support from: Janssen Research and Development, LLC, S. Chakravarty Employee of: Janssen Scientific Affairs, LLC, S. Kafka Employee of: Janssen Scientific Affairs, LLC, D Harrison Employee of: Janssen Research and Development, LLC, D. Parenti Employee of: Janssen Scientific Affairs, LLC, L. Kim Employee of: Janssen Research and Development, LLC, K. Lo Employee of: Janssen Research and Development, LLC, E. Hsia Employee of: Janssen Research and Development, LLC, A. Kavanaugh Grant/research support from: Janssen Research and Development, LLC

DOI: 10.1136/annrheumdis-2018-eular.1766

\section{SAT0347 BASELINE CHARACTERISTICS OF PATIENTS WITH PSORIATIC ARTHRITIS INITIATED ON APREMILAST IN THE CORRONA PSORIATIC ARTHRITIS/ SPONDYLOARTHRITIS (PSA/SPA) REGISTRY}

P.J. Mease $^{1}$, E. Rosenstein ${ }^{2}$, H. Feng ${ }^{3}$, M. Liu ${ }^{3}$, B. Guerette ${ }^{4}$, L. Teng ${ }^{4}$, S. Rebello ${ }^{3}$, A.R. Ogdie-Beatty ${ }^{5} .{ }^{1}$ Swedish Medical Center and University of Washington School of Medicine, Seattle; ${ }^{2}$ Institute for Rheumatic and Autoimmune Diseases, Overlook Medical Center, Summit, ${ }^{3}$ Corrona, LLC, Southborough; ${ }^{4}$ Celgene Corporation, Summit; ${ }^{5}$ Department of Medicine, Division of Rheumatology, University of Pennsylvania, Philadelphia, USA

Background: Apremilast (APR) is an oral phosphodiesterase 4 inhibitor approved for the treatment of adult patients with active psoriatic arthritis (PsA) and psoriasis.

Objectives: To characterise demographics, disease activity and duration, concomitant therapy, quality of life, and prior comorbidities among patients with PsA who initiated APR in the Corrona Psoriatic Arthritis/Spondyloarthritis (PsA/SpA) registry, an independent, prospective, US observational cohort.

Methods: Adult patients $\geq 18$ years of age with PsA who were reported initiating APR in the Corrona PsA/SpA registry between May 2014 and September 2017 were included in the analysis. Descriptive statistics were calculated for patients' clinical characteristics and disease assessments at the index visit. The index visit was defined as the Corrona visit when APR initiation was reported. If the patient started a drug between 2 Corrona visits, the measures/outcomes from a prior visit were imputed to replace the missing values.

\begin{tabular}{|c|c|c|}
\hline \multicolumn{3}{|c|}{ Clinical Characteristics and Disease Assessments of PsA/SpA Patients at the Index Visit } \\
\hline Characteristic & $\mathbf{n}^{*}$ & Mean (SD) \\
\hline Swollen joint count (0-66) & 136 & $2.7(4.43)$ \\
\hline Tender joint count $(0-68)$ & 136 & $7.2(11.56)$ \\
\hline PhGA (VAS 0-100 mm) & 135 & $22.1(18.82)$ \\
\hline PtGA (VAS 0-100 mm) & 134 & $54.2(26.45)$ \\
\hline Dactylitis count (1-20) & $14 / 138$ & $2.6(2.21)^{5}$ \\
\hline SPARCC/Leeds Enthesitis Index (1-16) & $34 / 138$ & $4.2(3.05)^{5}$ \\
\hline DAS-28 (CRP) $(0-10)$ & 67 & $3.1(1.04)$ \\
\hline CDAl (0-76) & 128 & $13.9(9.57)$ \\
\hline CDAPSA $(0-154)$ & 128 & $20.7(15.07)$ \\
\hline HAQ-S (0-3) & 135 & $0.95(0.69)$ \\
\hline $\operatorname{BASDAI}(0-10)$ & 126 & $5.4(2.53)$ \\
\hline Morming stiffness (VAS 0-100 mm) & 134 & $54.4(28.26)$ \\
\hline \multicolumn{3}{|c|}{ 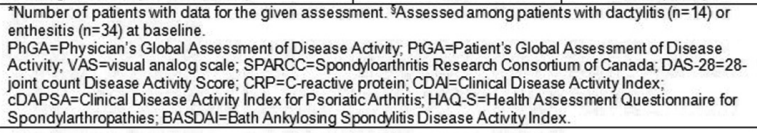 } \\
\hline
\end{tabular}

Results: Among 138 patients included in the analysis, mean (SD) age was $56^{12}$ years, mean (SD) BMI was $33,{ }^{7} 62 \%$ were female, $66 \%$ were previously on a nonbiologic DMARD (nbDMARD) and $79 \%$ had prior biologic use; $62 \%$ were on APR monotherapy. Of the APR initiators, the number of patients receiving concomitant methotrexate, nbDMARD, TNF inhibitor, and non-TNF inhibitor were 32 (23\%), 41 $(30 \%), 6(4 \%)$, and $4(3 \%)$, respectively. Pertinent comorbidities included diabetes mellitus $(22 \%)$, metabolic syndrome $(22 \%)$, cancer $(18 \%)$, cardiovascular disease $(17 \%)$, and congestive heart failure $(0.7 \%)$. Patients reported a mean (SD) of $13^{10}$ years for PsA symptoms and a mean (SD) of $10^{9}$ years since PsA diagnosis. Of the 94 patients with data available for evaluation, $14 \%$ met criteria for minimal disease activity while $1 \%$ met criteria for very low disease activity. Most patients had moderate or low levels of disease activity, respectively: CDAI (48\% and $35 \%)$, cDAPSA ( $47 \%$ and $34 \%$ ), and DAS-28 (CRP) (37\% and $21 \%$ ). Of note, $82 \%$ of patients had $<5$ swollen joints and $63 \%$ had $<5$ tender joints. Mean HAQ-S $(0-3)$ was 0.95 and BASDAI $(0-10)$ was 5.4 (Table). Patients demonstrated a substantial burden of disease with a mean fatigue score $(0-100)$ of 55 and mean overall pain score $(0-100)$ of 55 , and $81 \%$ reported stiffness lasting $>30$ min. Additionally, mean baseline work productivity and activity impairment (WPAI) subscale scores indicated limitations on absenteeism (8\%), presenteeism (25\%), work productivity loss (26\%), and activity impairment (40\%).

Conclusions: The population of patients with PsA treated with APR in the Corrona $\mathrm{PsA} / \mathrm{SpA}$ registry exhibited low to moderate disease activity and were substantially impacted, as evidenced by patient-reported outcomes (pain, fatigue, stiffness, and productivity). Future analyses on this cohort will provide more insight into patient characteristics and treatment patterns in this population, as well as long-term efficacy and safety information for PsA patients treated with APR.

Disclosure of Interest: P. Mease Grant/research support from: Abbott, Amgen, Biogen Idec, BMS, Celgene Corporation, Genentech, Janssen, Eli Lilly, Novartis, Pfizer, Roche, UCB, Consultant for: Abbott, Amgen, Biogen Idec, BMS, Celgene Corporation, Genentech, Janssen, Eli Lilly, Novartis, Pfizer, Roche, UCB, Speakers bureau: Abbott, Amgen, Biogen Idec, BMS, Genentech, Janssen, Eli Lilly, Pfizer, UCB, E. Rosenstein Grant/research support from: Biogen, Boehringer Ingelheim, Novartis, Consultant for: BMS, Boehringer Ingelheim, Speakers bureau: Amgen, BMS, H. Feng Employee of: Corrona, LLC, M. Liu Employee of: Corrona, LLC, B. Guerette Employee of: Celgene Corporation, L. Teng Employee of: Celgene Corporation, S. Rebello Employee of: Corrona, LLC, A. Ogdie-Beatty Grant/research support from: Pfizer, Novartis, Consultant for: Abbvie, BMS, Lilly, Pfizer, Novartis, Takeda

DOI: 10.1136/annrheumdis-2018-eular.3361

\section{SAT0348 SAFETY OF IXEKIZUMAB IN PATIENTS WITH PSORIATIC ARTHRITIS: RESULTS FROM A POOLED ANALYSIS OF THREE CLINICAL TRIALS}

P. Goupille ${ }^{1}$, E. Roussou ${ }^{2}$, G. Burmester ${ }^{3}$, P.J. Mease ${ }^{4}$, A.B. Gottlieb ${ }^{5}$, S. Garces ${ }^{6}$, O. Benichou ${ }^{7}$, D. Adams ${ }^{6}$, W. Xu ${ }^{6}$, P. Nash ${ }^{8} .{ }^{1}$ University Hospital of Tours, Tours, France; ${ }^{2}$ King George Hospital, Essex, UK; ${ }^{3}$ Charité — University Medicine Berlin Free University and Humboldt University, Berlin, Germany; ${ }^{4}$ Swedish Medical Center, and University of Washington, Seattle; ${ }^{5}$ New York Medical College, New York; ${ }^{6}$ Eli Lilly and Company, Indianapolis, USA; ${ }^{7}$ Eli Lilly and Company, Paris, France; ${ }^{8}$ University of Queensland, Brisbane, Australia

Background: Ixekizumab (IXE), a high affinity monoclonal antibody that selectively targets interleukin-17A, has been shown to be superior to placebo (PBO) in improving signs and symptoms of psoriatic arthritis (PSA) in Phase 3 trials ${ }^{1,2}$.

Objectives: To assess the safety of IXE in patients with active PsA using data pooled from 3 (SPIRIT-P1, -P2, and -P3) Phase 3 trials.

Methods: SPIRIT-P $1^{1}$ and $-\mathrm{P} 2^{2}$ are double-blind trials; patients were randomised to $\mathrm{PBO}$, adalimumab (ADA; active reference arm; SPIRIT-P1 only), ${ }^{1}$ or $80 \mathrm{mg}$ IXE every $4(\mathrm{Q} 4 \mathrm{~W})$ or 2 (Q2W) weeks. PBO and ADA patients were re-randomised to either IXEQ4W or IXEQ2W for the open-label extension period (Weeks 24-156); patients who initially received IXE remained on their original dose. SPIRIT-P3 is an open-label (Week 36-64) trial where patients received IXEQ2W followed by a randomised withdrawal period. In all the 3 trials, patients received a $160 \mathrm{mg}$ loading dose of IXE. Safety data were integrated from all IXE-treated patients (defined as all patients receiving $\geq 1$ dose of IXE) included in SPIRIT-P1, -P2, and -P3. Exposure-adjusted incidence rates (IRs) per 100 patient-years (PY) were reported for adverse events (AEs).

Results: Overall, 1118 patients received IXE (total exposure $=1373.4$ PY). Four deaths (0.3/100PY) were reported (cerebrovascular accident, cardio-respiratory arrest, drowning, and pneumonia) (Table). The most common treatment-emergent AEs (TEAEs) were injection-site reaction (ISRs), upper respiratory tract infection, and nasopharyngitis; IRs for TEAEs, including ISRs, decreased overtime. There was no clinically meaningful increase in IRs of serious AEs, infections, serious infections, hypersensitivity, and major adverse cardiovascular events (MACE) with longer IXE exposure (Table). IR for serious infections was low (1.2/ 100PY). Serious infections included pneumonia (0.2/100PY), lower respiratory tract infection, and esophageal candidiasis (0.1/100PY each). No case of active tuberculosis (TB) was reported, but 1 case of latent TB was deemed as serious due to hospitalisation for testing to exclude active TB. Opportunistic infections were limited to oral and esophageal Candida and localised herpes zoster. There were no reports of deep organ or bloodstream Candida infections. No anaphylaxis was reported, but 1 patient $(0.1 / 100 \mathrm{PY})$ experienced angioedema. No patient had infections temporally associated with Grade $\geq 2$ neutropenia. Nine patients $(0.7 /$ $100 \mathrm{PY}$ ) had MACE. One case (0.1/100PY) each of Crohn's disease (with prior history of irritable bowel syndrome) and ulcerative colitis were reported. However, none of the 12 patients with pre-existing inflammatory bowel disease experienced an exacerbation with IXE. 
Abstract SAT0348 - Table 1. Exposure-Ajusted Incidence Rate of TEAEs at 12-Week Intervals up to Week 96 (All PsA Ixekizumab Exposures Integrated Analysis Set: SPIRIT-P1, SPIRIT-P2, and SPIRIT-P3).

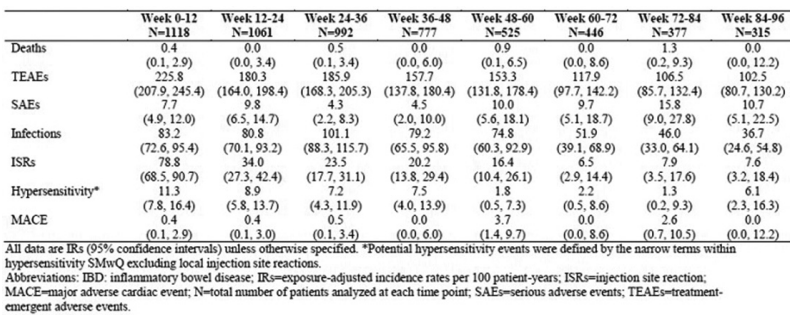

Conclusions: The safety profile of IXE in patients with PSA is consistent with previous reports as derived from the analysis of the three SPIRIT trials from a large cohort of patients. No new safety signals were identified with longer IXE treatment exposure.

\section{REFERENCES:}

[1] Mease PJ, et al. ARD 2017;76:79.

[2] Nash P, et al. Lancet 2017;10:2317.

Disclosure of Interest: P. Goupille Consultant for: Abbvie, BMS, Biogaran, Celgene, Eli Lilly and Company, Janssen, MSD, Novartis, Pfizer, UCB, E. Roussou Grant/research support from: Pfizer, MERCK, Eli-Lilly, TAKEDA, UCB, G. Burmester Grant/research support from: Eli Lilly and company, Consultant for: Novartis, Pfizer, Janssen, Eli Lilly, P. Mease Grant/research support from: AbbVie, Amgen, Bristol-Myers Squibb, Celgene, SUN, Eli Lilly, Genentech, Janssen, Merck, Novartis, Pfizer, UCB, Consultant for: AbbVie, Amgen, Bristol-Myers Squibb, Celgene, SUN, Eli Lilly, Genentech, Janssen, Merck, Novartis, Pfizer, UCB, Speakers bureau: AbbVie, Amgen, Bristol-Myers Squibb, Celgene, Novartis, Eli Lilly, Genentech, Janssen, Pfizer, and UCB, A. B. Gottlieb Grant/research support from: Janssen, Incyte, Consultant for: Celgene Corp., Bristol Myers Squibb Co., Beiersdorf, Inc., Abbvie, UCB, Novartis, Incyte, Lilly, Reddy Labs, Valeant, Dermira, Allergan, Sun Pharmaceutical Industries, S. Garces Shareholder of: Eli Lilly and Company, Employee of: Eli Lilly and Company, O. Benichou Shareholder of: Eli Lilly and Company, Employee of: Eli Lilly and Company, D. Adams Shareholder of: Eli Lilly and Company, Employee of: Eli Lilly and Company, W. Xu Shareholder of: Eli Lilly and Company, Employee of: Eli Lilly and Company, P. Nash Grant/research support from: AbbVie, Amgen, Bristol-Myers Squibb, Celgene, Eli Lilly and Company, Hospira, Janssen, MSD, Novartis, Pfizer, Roche, Sanofi, UCB, Consultant for: AbbVie, Amgen, Bristol-Myers Squibb, Celgene, Eli Lilly and Company, Hospira, Janssen, MSD, Novartis, Pfizer, Roche, Sanofi, UCB, Speakers bureau: AbbVie, Amgen, Bristol-Myers Squibb, Celgene, Eli Lilly and Company, Hospira, Janssen, MSD, Novartis, Pfizer, Roche, Sanofi, UCB

DOI: 10.1136/annrheumdis-2018-eular.2132

\section{SAT0349 A NOVEL SCORING SYSTEM TO DIFFERENTIATE PSORIATIC ARTHRITIS FROM NODAL OSTEOARTHRITIS ON PLAIN-FILM RADIOGRAPHS}

R. Mandegaran ${ }^{1}$, E. Nikiphorou ${ }^{2}$, S. Bahadur ${ }^{3}$, C. Hughes $^{3}$, B. Kirkham ${ }^{3}$ A. Zavareh ${ }^{1}$. ${ }^{1}$ Radiology, Guy's and St Thomas' NHS Foundation Trust; ${ }^{2}$ Academic Rheumatology Department, King's College London; ${ }^{3}$ Rheumatology, Guy's and St Thomas' NHS Foundation Trust, London, UK

Background: Differentiating Psoriatic Arthritis (PsA) and Nodal Osteoarthritis (NOA) in patients with interphalangeal joint (IPJ) involvement is often challenging. ${ }^{1-3}$ Yet, the distinction is important to make, especially as the treatment for these conditions is vastly different. Here we present a novel scoring system based on identifying often subtle but characteristic radiographic features of both conditions on bilateral hand plain-film radiographs.

Objectives: To describe the key radiographic discriminating features that underpin a new scoring system aimed primarily to differentiate PsA from NOA.

Methods: The initial scoring methodology was tested through blind analysis and scoring of 99 bilateral hand radiographs of patients with a confirmed clinical diagnosis of PsA, NOA and RA. ${ }^{4}$ In this initial study, anonymised radiographs were read by a Musculoskeletal Radiologist blinded to all clinical information. The reader correctly identified the clinical diagnosis in $100 \%$ of radiographs. The analysis method was taught to 3 specialist trainees, in a 1 hour training session. They assessed the same radiograph series with an accuracy of $67 \%-88 \%$.

We refined the radiograph analysis method to develop a scoring system by developing weighted scores for different PsA arthropathic features. These include periarticular erosions and new bone formation (NBF), reduced joint space, soft tissue oedema and asymmetry of findings. Osteoarthritis features included marginal osteophytes, subchondral sclerosis/cysts and reduced joint space.

Results: All bilateral interphalangeal joints and 1 st metacarpophalangeal (MCP) joint are assessed - (20 joints in total). First carpo-metacarpal joint changes were more common in NOA, but had little discriminatory value. Periarticular erosion and NBF are the key indicators and either feature must be present on the radiographs. Asymmetry of the findings and soft tissue oedema are also included. Each radiographic feature is scored between 0 and $2(0=$ normal, $1=\mathrm{mild} / \mathrm{moder}$ ate, $2=$ severe). The scoring system allows the identification of PsA features, even in the presence of background NOA. This scoring system is currently undergoing validation.

Conclusions: This radiographic interpretation and scoring system provides a clear framework with key discriminators and relative major and minor weighting Once validated, it could be taught and used as a readily available, low-cost imaging tool, by both radiologists and non-radiologists alike.

\section{REFERENCES:}

[1] McGonagle D. Imaging the joint and enthesis: insights into the pathogenesis of psoriatic arthritis. Ann Rheum Dis. 2005;64[supple 2]:ii58-ii60.

[2] Offidani A, Cellini A, Valeri G, Giovagnoni A. Subclinical joint involvement in psoriasis: magnetic resonance imaging and $x$-ray findings. Acta Derm Venereol 1998;78:463-465.

[3] Spira D, Kotter I, Henes J, et al. MRI findings in psoriatic arthritis of the hands. AJR Am J Roentgenol 2010;195:1187-1193.

[4] Bahadur S, et al. Psoriatic arthritis and nodal osteoarthritis can be differentiated using hand radiographs: a novel method, EULAR 2017.

Disclosure of Interest: R. Mandegaran: None declared, E. Nikiphorou: None declared, S. Bahadur: None declared, C. Hughes: None declared, B. Kirkham Grant/research support from: Abbvie, Novartis, Roche, UCB, Paid instructor for: Eli Lilly and Co, Janssen, Novartis, A. Zavareh: None declared DOI: 10.1136/annrheumdis-2018-eular.7462

\section{SAT0350 CONTENT AND FACE VALIDITY AND FEASIBILITY OF FIVE CANDIDATE INSTRUMENTS FOR PSORIATIC ARTHRITIS RANDOMISED CONTROLLED TRIALS: RESULTS FROM THE PSA OMERACT CORE SET WORKSHOP AT THE GRAPPA 2017 ANNUAL MEETING}

R. Holland ${ }^{1}$, W. Tillett ${ }^{1}$, A. Ogdie ${ }^{1}$, Y.Y. Leung ${ }^{1}$, D.D. Gladman ${ }^{1}$, K. Callis Duffin ${ }^{1}$, L. C. Coates ${ }^{1}$, P. Mease ${ }^{1}$, L. Eder ${ }^{1}$, V. Strand ${ }^{1,2}$, M. Elmamoun ${ }^{1}$, P. Højgaard ${ }^{1}$, I. Campbell ${ }^{1}$, J. Chau ${ }^{1}$, M. de Wit ${ }^{1}$, N. Goel ${ }^{1}$, C.A. Lindsay ${ }^{1}$, O. FitzGerald ${ }^{1}$, B. Shea ${ }^{2}$, D. Beaton ${ }^{2}$, A.-M. Orbai ${ }^{1}$. 'Grappa-omeract PSA Core Set Working Group; ${ }^{2}$ Outcome Measures in Rheumatology, International Organisation,

Background: The Group for Research and Assessment of Psoriasis and Psoriatic Arthritis (GRAPPA) - Outcome Measures in Rheumatology (OMERACT) Psoriatic Arthritis (PsA) Core Set working group is developing a core instrument set to guide selection of outcome measures (instruments) for PsA randomised controlled trials (RCTs) and longitudinal observational studies (LOS). Candidate instrument measurement properties are being appraised in systematic literature reviews by working group members.

Objectives: Appraise the content and face validity (domain match) and feasibility of PsA instruments with GRAPPA stakeholders using the OMERACT Filter 2.1 instrument selection process ${ }^{1}$.

Methods: The PsA Core set workshop held at the GRAPPA 2017 annual meeting comprised an introductory plenary session and breakout group discussions Working group members facilitated six breakout groups, with two patient research partners (PRPs) per group, discussing pre-selected domain-instrument pairs. Participants individually reviewed the instrument(s). After group discussion, they completed anonymised paper-based OMERACT questionnaires examining domain match and feasibility, with votes for each aspect of domain match and feasibility centralised by instrument. A final vote (show of hands) on whether the assigned instrument met the requirements for domain match and feasibility using the OMERACT traffic-light scoring system was taken. Consensus was defined as more than $70 \%$ agreement, and majority as more than $50 \%$ agreement within a group. Consensus represents stronger evidence than majority agreement.

Results: There were 145 participants across all breakout groups and 116 returned completed questionnaires. Anonymized votes are summarised across groups and instruments in figure 1. More than $70 \%$ in the respective breakout groups endorsed the PsA instrument 66 swollen and 68 tender joint count $(66 / 68$ SJC/TJC) as a good match with the target domain of arthritis, a subset of MSK disease activity, FACIT-Fatigue as a good match with fatigue, and PSAID12 as a good match with HRQoL. There was consensus or majority agreement for all feasibility questions for the 66/68 SJC/TJC, HAQ-DI and PsAID9 and PsAID12. For the SPARCC enthesitis index only one item in both domain match and feasibility did not reach majority agreement. 